\title{
Werken en leren in openbaar bestuur en overheidsdiensten
}

Citation for published version (APA):

Fouarge, D., de Grip, A., Künn, A., Peeters, T., \& Poulissen, D. (2019). Werken en leren in openbaar bestuur en overheidsdiensten. ROA. ROA Fact Sheets No. 002 https://doi.org/10.26481/umarof.2019002

Document status and date:

Published: 25/02/2019

DOI:

10.26481/umarof.2019002

Document Version:

Publisher's PDF, also known as Version of record

\section{Please check the document version of this publication:}

- A submitted manuscript is the version of the article upon submission and before peer-review. There can be important differences between the submitted version and the official published version of record.

People interested in the research are advised to contact the author for the final version of the publication, or visit the DOI to the publisher's website.

- The final author version and the galley proof are versions of the publication after peer review.

- The final published version features the final layout of the paper including the volume, issue and page numbers.

Link to publication

\footnotetext{
General rights rights.

- You may freely distribute the URL identifying the publication in the public portal. please follow below link for the End User Agreement:

www.umlib.nl/taverne-license

Take down policy

If you believe that this document breaches copyright please contact us at:

repository@maastrichtuniversity.nl

providing details and we will investigate your claim.
}

Copyright and moral rights for the publications made accessible in the public portal are retained by the authors and/or other copyright owners and it is a condition of accessing publications that users recognise and abide by the legal requirements associated with these

- Users may download and print one copy of any publication from the public portal for the purpose of private study or research.

- You may not further distribute the material or use it for any profit-making activity or commercial gain

If the publication is distributed under the terms of Article $25 \mathrm{fa}$ of the Dutch Copyright Act, indicated by the "Taverne" license above, 
Research Centre for Education and the Labour Market | ROA

\section{Werken en leren in openbaar bestuur en overheidsdiensten}

\section{ROA Factsheet}

ROA-F-2019/2

Researchcentrum voor Onderwijs en Arbeidsmarkt | ROA Research Centre For Education and the Labour Market / ROA 


\section{WERKEN EN LEREN IN OPENBAAR BESTUUR EN OVERHEIDSDIENSTEN}

Factsheet ROA-F-2019/2

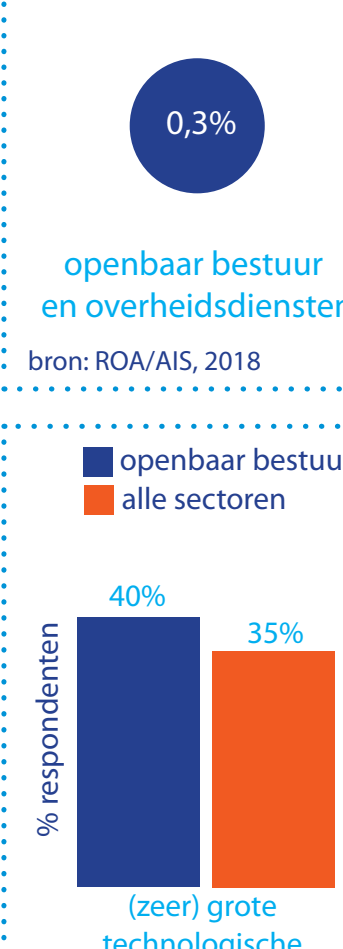

technologische

bron: ROA LLL-Enquête, 2017

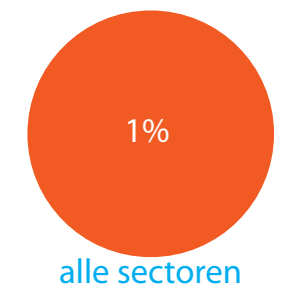
geheel.

of zeer grote technologische en organisatorisch

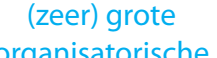

organisatorisch
ontwikkelinge

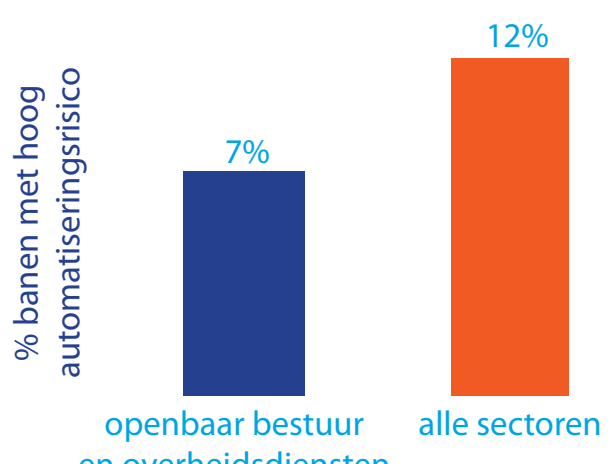

en overheidsdiensten

bron: OESO, 2018
Verwachte jaarlijkse

werkgelegenheidsgroei tot 2022

De jaarlijkse werkgelegenheidsgroei tot 2022 in de sector is veel lager dan voor Nederland als

Technologische en

organisatorische ontwikkelingen

Werkenden in de sector openbaar bestuur en

overheidsdiensten geven vaker aan dat er grote

ontwikkelingen in hun werk plaatsvinden dan gemiddeld over alle sectoren.

- vijf grootste beroepsgroepen in de sector dere beroepsgroepen

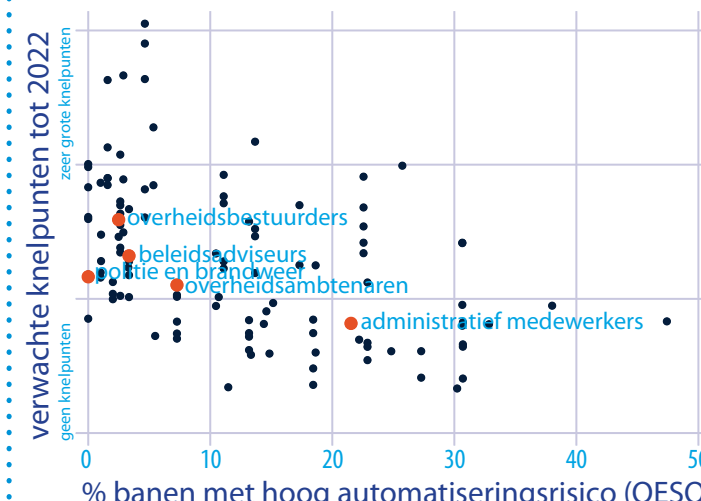

Automatisering en leren

- De trainingsdeelname van politie brandweer en administratief medewerkers is veel lager dan bij beleidsadviseurs, overheidsambtenaren en overheidsbestuurders.

- vijf grootste beroepsgroepen in de sector

\section{Automatiseringsrisico}

$7 \%$ van de banen in de sector kent een groot automatiseringsrisico, ten opzichte van gemiddeld $12 \%$ van de banen in alle sectoren kleiner is. knelpunten.

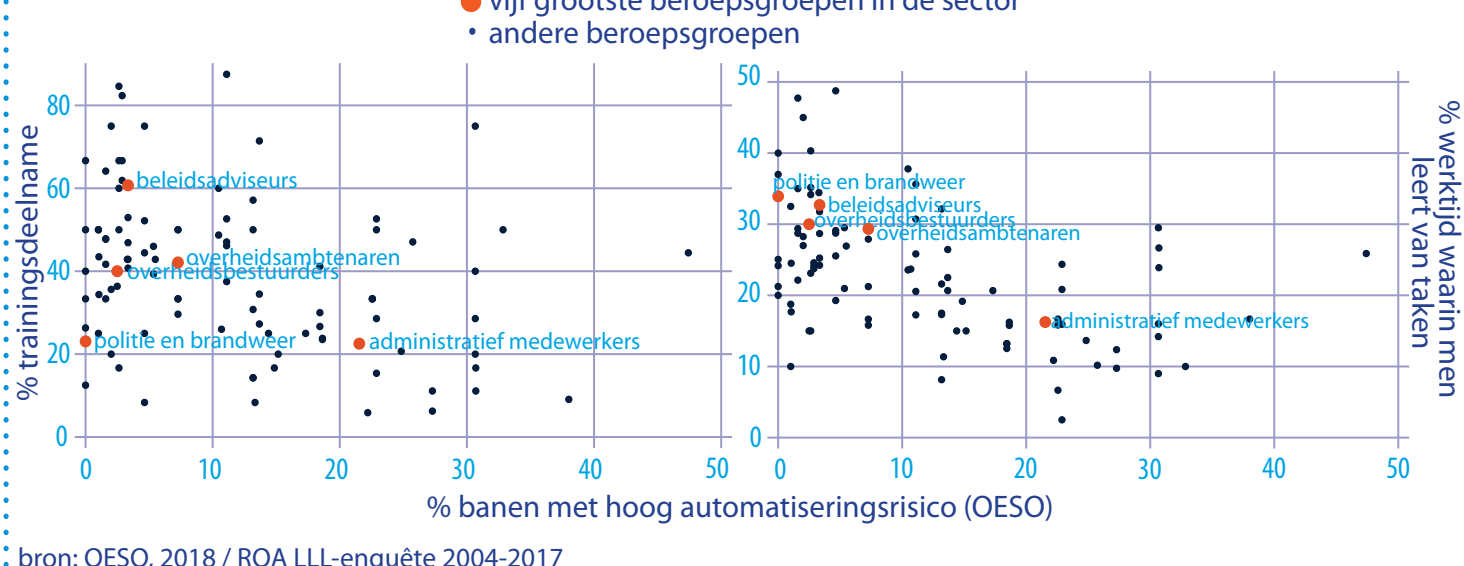

bron: OESO, 2018 / ROA LLL-enquête 2004-2017
Verwachte arbeidsmarkt-

knelpunten tot 2022 en

automatiseringsrisico

De verwachte knelpunten naar beroep zijn groter naarmate het automatiseringsrisico

- Vervan de vif grootste beroepsgroepen in de sector kennen een gemiddeld of laag automatiseningsisico en een naar verwachting vrij gemiddeld aanta

Administratief medewerkers kennen zowel het grootste risico op automatisering als de minste verwachte knelpunten

- In de sector wordt in het algemeen minder geleerd van het uitvoeren van taken

.

Administratief medewerkers leren aanzienlijk minder van taken op het werk dan de vier andere grootste roepsgroepen in de sector.

vijf grootste beroepsgroepen

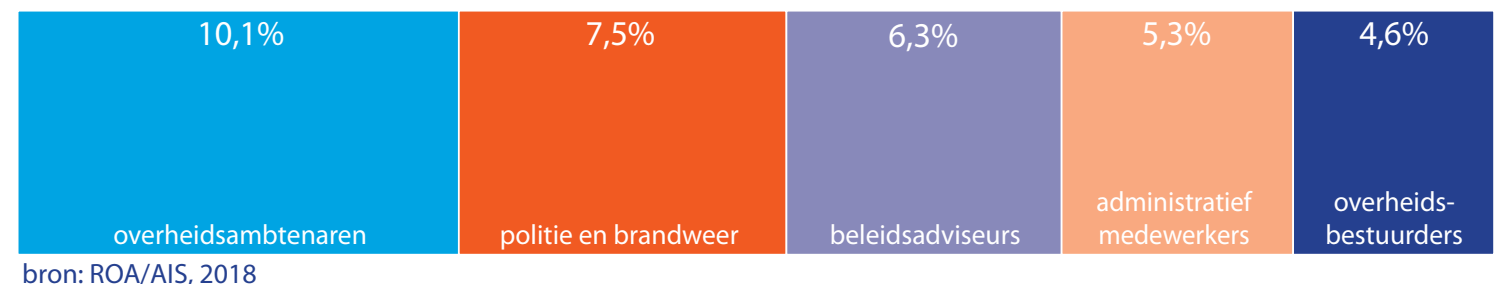

Cursusdeelname

Elke twee jaar neemt ongeveer $65 \%$ van de werkenden in de sector deel aan trainingen.

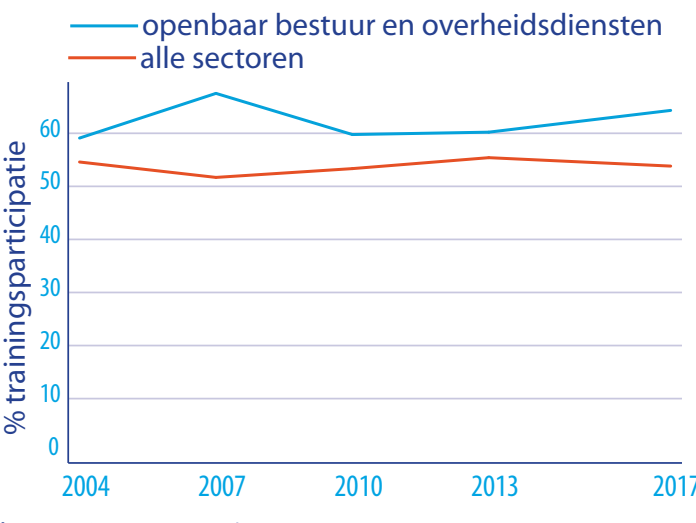

bron: ROA LLL-Enquête, 2004-2017

Werktijd besteed aan taken waarvan men leert

Werkenden in de sector besteedden in 2017 ongeveer $25 \%$ van hun werktijd aan taken waarvan ze leerden.

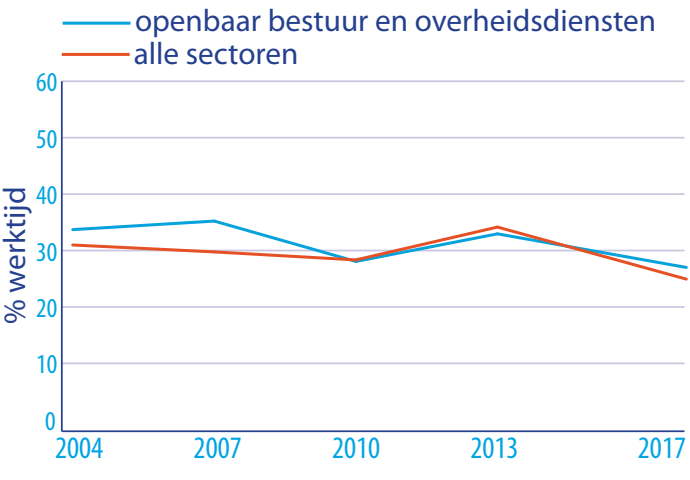

bron: ROA LLL-Enquête, 2004-2017 


\section{Over de data}

1. Het ROA brengt het formele en informele leren in kaart aan de hand van de ROA Levenslang Leren Enquête (ROA LLL). Deze enquête is gehouden onder een representatieve steekproef van de Nederlandse beroepsbevolking in de jaren 2004, 2007, 2010, 2013 en 2017. De hieruit gebruikte data hebben betrekking op personen die aangeven betaald werk te verrichten.

2. De prognosecijfers zijn afkomstig van het NRO-project Onderwijs-Arbeidsmarkt: http://roa.sbe.maastrichtuniversity.nl/?portfolio=poa-project-onderwijs-arbeidsmarkt-2

3. De verwachte knelpunten zijn bepaald volgens de Indicator Toekomstige Knelpunten naar Beroep (ITKB). De ITKB geeft de kans weer dat de gewenste personeelssamenstelling naar opleiding binnen beroepsgroepen gerealiseerd kan worden, rekening houdend met het verwachte aanbod per opleiding.

4. Data over het automatiseringsrisico is afkomstig van Nedelkoska, L, \& Quintini, G. (2018). Automation, skills and training. Paris: OESO.

\section{Contactpersonen}

Didier Fouarge, d.fouarge@maastrichtuniversity.nl Andries de Grip, a.degrip@maastrichtuniversity.nl

Deze factsheet maakt onderdeel uit van het NRO-project 'Levenslang leren en competentieontwikkeling' (dossiernummer 405-16-402) en het ROA-project Onderwijs-Arbeidsmarkt (dossiernummer 405-17-900).

\section{Colofon}

() Researchcentrum voor Onderwijs en Arbeidsmarkt Niets uit deze uitgave mag op enige manier worden verveelvoudigd zonder voorafgaande schriftelijke toestemming van de directeur van het ROA.

\section{Researchcentrum voor Onderwijs en Arbeidsmarkt}

Maastricht University

School of Business and Economics

secretary-roa-sbe@maastrichtuniversity.nl www.roa.nl

\section{Vormgeving}

ROA secretariaat, Maastricht

\section{februari 2019}

